Cowan, S. T. (1953). J. gen. Microbiol. 8, 391-396.

\title{
Fermentations: Biochemical Micromethods for Bacteriology
}

\author{
By S. T. COWAN \\ National Collection of Type Cultures, Colindale Avenue, London, N.W. 9
}

\begin{abstract}
SUMMARY: Discrepancies found in the use of three previously published micromethods for fermentations were traced to at least three possible sources of error: contamination of the water used for making suspensions; contamination of capillary tests from non-sterilizable Perspex plates; chemical breakdown or contamination of certain sugar solutions. To overcome these discrepancies one of the methods was modified; the other two were abandoned.

Suspension concentration is important and, measured as opacity, should not be less than the equivalent of $10^{9}$ Bacterium coli cells $/ \mathrm{ml}$. Sugar concentration is much less critical, and $0 \cdot 1 \mathrm{~m}$ concentrations are recommended. Dilution of the test mixture with $0.5 \mathrm{ml}$. sterile water speeds up fermentations; the addition of formalin or thiomersalate inhibits certain enzyme systems but does not hinder glucose fermentation.
\end{abstract}

Micromethods to test the biochemical activity of bacteria in non-multiplying suspensions were described by Clarke \& Cowan (1952); extended trial has shown their usefulness and also some of their limitations. As originally described, the tests used techniques common in biochemical laboratories for experiments of short duration, but their application to bacterial fermentations often demanded prolonged incubation before a final reading was taken. Attention was at first concentrated on single tests on a wide variety of strains, and it was not then obvious that erroneous results were sometimes being obtained; fermentation in a microtest which was not paralleled by fermentation of the same sugar in peptone water was thought to be due to a masking effect of alkaline products from peptone breakdown by the growing culture. Several months later many strains were re-examined, and when, as sometimes happened, different results were obtained in the microtest, our explanation of discrepancies seemed to be false, or, at the best, only a half-truth. This paper records examples of misleading results, explanations of their probable causes, and modifications of technique necessary to avoid their repetition.

\section{EXPERIMENTAL}

\section{Example of erroneous result}

In the original method (Clarke \& Cowan, 1952) growths were washed off agar slope cultures and were resuspended in unsterilized tap water. Usually these suspensions were satisfactory, but at times we observed examples of unexpected acid production in sugar solutions that were chemically satisfactory. In November and December 1951 several strains of Bacterium alcaligenes, Brucella spp., and Haemophilus bronchisepticus were tested and acid was produced, usually after overnight incubation, from many of the 
sugar solutions. When retested in January 1952, entirely different results were obtained, and few of the strains showed any fermentative ability. On 5 February 1952, NCTC 655 (Bacterium alcaligenes) was examined by the routine microtests; acid was produced from several sugars in the capillary fermentations (method 2 of Clarke \& Cowan), but not in open columns (method 3); in other biochemical tests, mostly read within a few hours, the

Table 1. Routine microtests on NCTC 655 and two contaminating strains, 655/A and 655/B

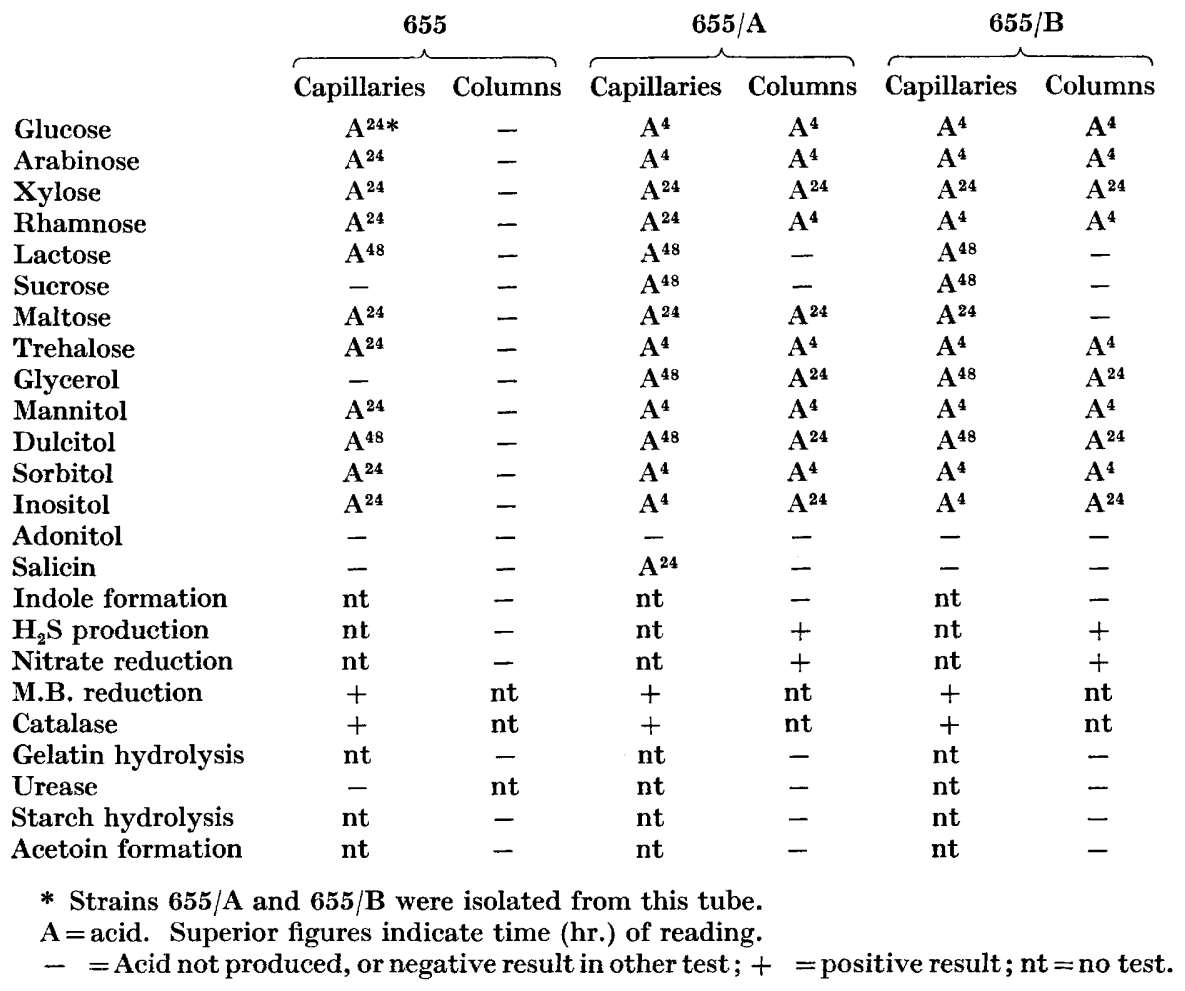

suspension seemed almost inactive. After $24 \mathrm{hr}$. incubation the capillary tube containing glucose and suspension was opened, the contents were diluted in broth and plated on MacConkey agar and on Lemco agar. Two types of colony $(655 / \mathrm{A}$ and $655 / \mathrm{B})$ grew on these plates and subcultures were put through the routine microtests. Both cultures were Gram-negative rods, and it was expected that one would be the original strain 655 , and the other a contaminant. The results ('Table 1) showed that neither colony type was descended from the original culture; that both were active fermenters of sugars in capillaries, open columns and in ordinary peptone-water cultures (not shown in the Table); that both produced $\mathrm{H}_{2} \mathrm{~S}$ and reduced nitrates to nitrites, characters not shown by NCTC 655 . When search was made, similar organisms were found occasionally in our tap water. 
Bigger (1937) found that certain coliform organisms could multiply in distilled water, while Allen, Pasley \& Pierce (1952) showed that Bact. coli grew when the medium was diluted to 10 parts/million parts water. It seemed probable that such an organism when contaminating our suspending fluid could multiply in the residual nutrient materials in our suspensions and ferment various sugar solutions. However, contaminating organisms from water were not the sole, or even the main, source of false fermentations. Table 1 shows that the suspension of 655 used on 5 February did not ferment sugars in the open columns (method 3). In comparative trials greater fermentative ability in capillary tubes was a constant finding; it was attributed, probably wrongly, to an anaerobic type of fermentation. By substituting sterile distilled water for the unsterilized tap water as suspending fluid the results with open columns (method 3) and tubes (method 1) became more consistent, but tests in capillaries continued on occasion to show irregular and unexpected fermentation.

Suspension + sugar mixtures for capillary tests presented a practical problem, namely, cross-contamination of sugar solutions and suspension. To avoid contamination of sugar solutions the capillaries were one-third filled with solution before being dipped into suspension; to avoid carry-over of sugar solution to the suspension, drops of suspension were pipetted into hollows in Perspex plates, one drop for each sugar, and from these drops the filling of the capillaries was completed; they were then two-thirds full and were sealed.

After use the Perspex plates were immersed in dilute $\mathrm{HCl}$ (5 vol. conc. $\mathrm{HCl}+95$ vol. $\mathrm{H}_{2} \mathrm{O}$ ) for $24 \mathrm{hr}$., washed in running tap water, drained, and the 80 hollows dried with a glass-cloth, clean on Mondays but soiled by Saturdays. These plates could not be heat sterilized before use, and they appeared to be the source of contaminating organisms responsible for false reactions in capillaries only. As a sterilizable substitute was not readily available, the obvious way to avoid carry-over seemed to be to use small test tubes; this would make a large addition to the washing up, or an extra manipulation to the test in small tubes (method 1). Consequently the capillary method was abandoned and attention directed to speeding up the method which used small tubes.

Other sources of error. Sugar solutions were sterilized either by momentary autoclaving (Davis \& Rogers, 1939) or by filtration, and were pipetted aseptically to sterile screw-capped bottles. When tested with Benedict's reagent, autoclaved sucrose solutions contained reducing substances which were absent from the original powdered sugar and from its solution. Sucrose would not tolerate even momentary autoclaving, and solutions were sterilized by Seitz filtration. However, occasional bottles of filtered sucrose showed reducing substances, and it is probable that traces of sugar may remain between the washer and the screw-cap, an experience similar to that of Allison \& Smyth (1945) when they used the same type of bottle as a sputum container. To overcome this difficulty new bottles and caps were clearly marked and used only for one sugar solution; metal caps and washers were separated and cleaned individually. 


\section{Factors affecting fermentation}

Before describing the modification finally developed it will be an advantage to outline the original method $\mathbf{1}$, and to show by experiment the effect of making changes, small in themselves, on the results. As originally described, method 1 (Clarke \& Cowan, 1952) was carried out in $65 \times 10 \mathrm{~mm}$. tubes which contained suspension, $\mathbf{0} \cdot \mathbf{2} \mathrm{ml}$; ; sugar solution, $\mathbf{0} \cdot \mathbf{1} \mathrm{ml}$; ; buffer + indicator solution (0.025 M-phosphate buffer, pH 6.8, $20 \mathrm{ml}$; $1 \%$ ethanolic bromcresol purple, $1.0 \mathrm{ml}$.), $\mathbf{0 . 2} \mathrm{ml}$; and the results were read after incubation in a waterbath at $37^{\circ}$.

Effect of suspension concentration. A suspension of a salmonella species was diluted tenfold, and $0.2 \mathrm{ml}$. volumes mixed with $0.1 \mathrm{ml} .25 \%$ glucose solution or $10 \%$ mannitol. The results are shown in Table 2 . All experiments in which the effect of suspension concentration was tested made it clear that a suspension was useless unless its opacity was at least as great as that of $10^{9}$ Bact. coli $/ \mathrm{ml}$.

Table 2. Effect of suspension concentration and dilution of the test mixture on the speed of acid production from glucose and mannitol by suspensions of cells of a salmonella species

\begin{tabular}{|c|c|c|c|c|}
\hline \multirow{3}{*}{$\begin{array}{l}\text { Suspension } \\
\text { concentration } \\
\text { (cells/ml.) }\end{array}$} & \multicolumn{2}{|c|}{ Microtest method 1} & \multicolumn{2}{|c|}{ Method $1+0.5 \mathrm{ml}$. water } \\
\hline & Glucose & Mannitol & Glucose & Mannitol \\
\hline & \multicolumn{4}{|c|}{ Time to first positive reading (hr.) } \\
\hline $10^{10}$ & 1 & 3 & 1 & 1 \\
\hline $10^{9}$ & $\mathbf{3}$ & 21 & 2 & 5 \\
\hline $10^{8}$ & 48 & - & 48 & - \\
\hline
\end{tabular}

Effect of dilution of test. Although suspension concentration is most important in these microtests, dilution of the whole test speeds up fermentation. Table 2 shows that the addition of $0.5 \mathrm{ml}$. sterile distilled water to each tube increased the speed of indicator change for all mixtures. This dilution effect appeared to be the result of weakening the phosphate buffer (Table 3). When the test is diluted with water the effect of the phosphate buffer is negligible, and it was omitted in the other experiments to be described. One other change was made; bromthymol blue was substituted for bromcresol purple so as to detect smaller changes in $\mathrm{pH}$ value.

Effect of bacteriostatics. Advantage was taken of the addition of diluent to test the effect of bacteriostatics. Glucose fermentation was almost inhibited by chloroform and toluene but not by suitable concentrations of Nipagin $\mathbf{M}$ (methyl- $p$-hydroxybenzoate), thiomersalate or formalin. Thiomersalate and formalin inhibited the fermentation of sucrose and lactose by many coliform organisms; only the fermentation of mannitol and sorbitol were unaffected by formalin.

Effect of sugar concentration. At first high concentrations of sugar were chosen for the microtests, and many solutions were near the limits of solu- 
bility of their sugars. Table 4 shows a comparison of results obtained with 52 strains, representative of the different genera in the family Bacteriaceae, in peptone-water cultures and when tested by a micromethod using strong

Table 3. Effect of dilution of test mixture when sugar concentration is varied

$\overbrace{25 \%}^{\text {Glucose }} \overbrace{25 \%}^{\text {Maltose }} \overbrace{2.5 \%}^{\text {Mannitol }} \overbrace{10 \%}^{\overbrace{1 \%} \%}$

Addition

\begin{tabular}{lcccccc}
\multicolumn{1}{c}{ Addition } & \multicolumn{1}{c}{ (1/4 } & 3 & 5 & $1 / 2$ & $1 / 2$ \\
None & $1 / 4$ & $1 / 4$ & 3 & 3 & $1 / 4$ & $1 / 4$ \\
Water & $1 / 4$ & $1 / 2$ & 24 & 24 & 24 & 3 \\
$0.01 \mathrm{M}$ buffer & $1 / 2$ & 3 & 24 & 24 & 24 & - \\
0.125 M buffer & 3 & $-=$ No change. & &
\end{tabular}

Table 4. Comparison of fermentation reactions of 52 strains of Bacteriaceae in peptone water cultures and in microtests using different concentrations of sugars

\begin{tabular}{|c|c|c|c|c|c|c|c|c|}
\hline & & & \\
\hline & \multirow{2}{*}{\multicolumn{2}{|c|}{ Peptone water }} & \multicolumn{3}{|c|}{$1 c$} & \multicolumn{3}{|c|}{$1 d$} \\
\hline & & & \multirow{3}{*}{$\begin{array}{c}\text { Sugar } \\
\text { concentration } \\
(\%)\end{array}$} & \multirow{2}{*}{\multicolumn{2}{|c|}{$\begin{array}{c}\text { No. of strains } \\
\text { reacting }\end{array}$}} & \multirow{3}{*}{$\begin{array}{c}\text { Sugar } \\
\text { concentration } \\
(\%)\end{array}$} & \multirow{2}{*}{\multicolumn{2}{|c|}{$\begin{array}{c}\text { No. of strains } \\
\text { reacting }\end{array}$}} \\
\hline & \multirow[b]{2}{*}{ Result } & \multirow{2}{*}{$\begin{array}{l}\text { No. of } \\
\text { strains }\end{array}$} & & & & & & \\
\hline & & & & + & - & & + & - \\
\hline Glucose & + & 52 & 25 & 52 & 0 & $1 \cdot 80$ & 52 & 0 \\
\hline \multirow[t]{2}{*}{ Arabinose } & + & 48 & 10 & 43 & 5 & $1 \cdot 50$ & 39 & 9 \\
\hline & - & 4 & & 1 & 3 & & 0 & 4 \\
\hline \multirow[t]{2}{*}{ Xylose } & + & 39 & 25 & 38 & 1 & $1 \cdot 50$ & 36 & 3 \\
\hline & - & 13 & & $\mathbf{5}$ & 8 & & 4 & 9 \\
\hline \multirow[t]{2}{*}{ Rhamnose } & + & 36 & 10 & 28 & 8 & $1 \cdot 82$ & 26 & 10 \\
\hline & - & 16 & & 3 & 13 & & 2 & 14 \\
\hline \multirow[t]{2}{*}{ Lactose } & + & 19 & 25 & 18 & 1 & $3 \cdot 60$ & 15 & 4 \\
\hline & - & 33 & & 4 & 29 & & 3 & 30 \\
\hline \multirow[t]{2}{*}{ Sucrose } & + & 14 & 25 & 11 & 3 & $3 \cdot 42$ & 11 & 3 \\
\hline & - & 38 & & 2 & 36 & & 3 & 35 \\
\hline \multirow[t]{2}{*}{ Maltose } & + & 43 & 25 & 41 & 2 & $3 \cdot 60$ & 40 & $\mathbf{3}$ \\
\hline & - & 9 & & 6 & 3 & & 2 & 7 \\
\hline \multirow[t]{2}{*}{ Trehalose } & + & 44 & 10 & 41 & $\mathbf{3}$ & $3 \cdot 42$ & 42 & 2 \\
\hline & - & 8 & & 3 & 5 & & 5 & 3 \\
\hline \multirow[t]{2}{*}{ Glycerol } & + & 46 & 25 & 46 & 0 & 0.92 & 46 & 0 \\
\hline & - & 6 & & 6 & 0 & & 6 & 0 \\
\hline \multirow[t]{2}{*}{ Mannitol } & + & 43 & 10 & 43 & o & $1 \cdot 82$ & 43 & 0 \\
\hline & - & 9 & & $\mathbf{3}$ & 6 & & 2 & 7 \\
\hline \multirow[t]{2}{*}{ Dulcitol } & + & 19 & 5 & 14 & 5 & $1 \cdot 82$ & 14 & $\mathbf{5}$ \\
\hline & - & 33 & & 2 & 31 & & 2 & 31 \\
\hline \multirow[t]{2}{*}{ Sorbitol } & + & 35 & 10 & 35 & 0 & 1.91 & 35 & 0 \\
\hline & - & 17 & & 10 & 7 & & 6 & 11 \\
\hline \multirow[t]{2}{*}{ Inositol } & + & 16 & 5 & 15 & 1 & $1 \cdot 80$ & 15 & 1 \\
\hline & - & 36 & & 2 & 34 & & 2 & 34 \\
\hline \multirow[t]{2}{*}{ Adonitol } & + & 10 & 5 & 8 & 2 & 1.52 & 8 & 2 \\
\hline & - & 42 & & 0 & 42 & & 0 & 42 \\
\hline \multirow[t]{2}{*}{ Salicin } & + & 19 & 5 & 13 & 6 & $2 \cdot 86$ & 12 & 7 \\
\hline & - & 33 & & 4 & 29 & & 3 & 30 \\
\hline
\end{tabular}


and weak solutions of sugar. A distinction was not made in the degree of acidity or speed of its production in the peptone-water cultures, which were read after 14 days incubation; microtests were read after $24 \mathrm{hr}$. From Table 4 the extent of the differences between the growing cultures and micromethods can be seen; it is also evident that the variation in sugar concentration does not have a great effect. The absence of negative tests with glycerol can probably be explained by impurities in the reagent.

\section{Modification of method}

During the course of experiments method 1 was modified several times. The final form (method $1 d$ ), which seems to give results most in agreement with the usual tests in growing cultures, is as follows:

Suspensions are made in sterile distilled water, $\mathrm{pH} 7 \cdot 6-7 \cdot 8$, from growth on a medium not containing a fermentable sugar. The diluting fluid used for the test is sterile distilled water, $\mathrm{pH} 7 \cdot 8-8 \cdot 0$, to which is added $5 \%(\mathrm{v} / \mathrm{v})$ bromthymol blue solution (British Drug Houses Ltd.). Mixtures are made in chemically clean $65 \times 10 \mathrm{~mm}$. tubes, and each tube contains, in order of addition: diluting fluid +indicator, $0.5 \mathrm{ml}$; $0.1 \mathrm{M}$ sugar solution, $0.05 \mathrm{ml}$; suspension, $0.05 \mathrm{ml}$. Tests are incubated in a water-bath at $37^{\circ}$ and readings made after 6 and $24 \mathrm{hr}$.

\section{DISCUSSION}

The evidence presented seems to justify the conclusion that fermentation tests cannot be looked upon simply as a biochemical problem; if pitfalls are to be avoided the methods must use bacteriological precautions to avoid contamination. In principle there is nothing wrong with the capillary method which uses little material and shows results quickly. In practice it is admirable for small-scale work, but for routine use it fails because of the technical difficulty of maintaining a reasonable degree of asepsis when making so many different mixtures. The mixtures can best be made in small test tubes, and to transfer the contents to capillary tubes is an unnecessary manipulation. Dilution of mixtures in the small tubes had the unexpected effect of speeding up the fermentations, and when advantage of this was taken the method was almost as rapid as the capillary test.

\section{REFERENCES}

Allen, L. A., Pasley, S. M. \& Pierce, M. A. (1952). Some factors affecting the viability of faecal bacteria in water. J. gen. Microbiol. 7, 36.

Alurson, V. D. \& Sмyth, J. A. (1945). Sources of error in the microscopic examination of specimens of sputum for tubercle bacilli. Mon. Bull. Minist. Hlth Lab. Serv. 4, 105-107.

BigGer, J. W. (1937). The growth of coliform bacilli in water. J. Path. Bact. 44, 167.

Clarke, P. H. \& Cowan, S. T. (1952). Biochemical methods for bacteriology. J. gen. Microbiol. 6, 187.

Davis, J. G. \& Rogers, H. J. (1939). The effect of sterilisation upon sugars. Z $b l$. Bakt. (2 Abt.), 101, 102. 